\title{
Os desafios da educação quilombola no Brasil: o território como contexto e texto
}

\author{
LOURDES DE FÁTIMA BEZERRA CARRIL
} Universidade Federal de São Carlos, Sorocaba, SP, Brasil

\section{RESUMO}

O reconhecimento legal dos quilombos no Brasil representa um marco histórico na visibilidade das diferenças étnicas e culturais da sociedade. $\mathrm{O}$ mito da democracia racial escondeu as dores da escravidão causando lesões nas identidades afrodescendentes. Analisando a luta pelo reconhecimento, percebe-se a necessidade de ampliação dos direitos, como é o da educação quilombola. Os desafios são grandes, sendo necessário modificar a cultura escolar, que exclui a diversidade. $\mathrm{Na}$ representação quilombola, não é o passado que retorna. É o presente que faz aflorar a história e a ancestralidade dentro das experiências que levam à organização social. Propostas educacionais que partam da etnicidade e da cultura podem abarcar o contexto e o texto territorial. Os quilombolas trazem o território que fala, por meio da história oral, possibilitando uma escuta desses significados.

PALAVRAS-CHAVE

territorialidade; etnicidade; educação quilombola. 


\title{
THE CHALLENGES FOR QUILOMBOLA EDUCATION IN BRAZIL: TERRITORIALITY AS CONTEXT AND TEXT
}

\begin{abstract}
The legal recognition of quilombos in Brazil represents a historical mark on the visibility of ethnical and cultural differences in the society. The myth of a racial democracy hid the pains of slavery causing injuries to the afrodescendants identities. By analyzing the struggle for recognition, we realized the need for expansion of rights, and quilombola education is among them. The challenges are big, as it is necessary to change the school culture which excludes diversity. In the quilombola representation, it is not the past that returns. It is the present that brings out the history and ancestry within the experiences that lead to social organization. Educational proposals that start from ethnicity and culture can embrace the context and the territorial text. The quilombolas bring the territoriality which speaks through the oral history, leading to the listening of these meanings.

KEYWORDS

territoriality; ethnicity; quilombola education.
\end{abstract}

\section{LOS RETOS DE LA EDUCACIÓN QUILOMBOLA EN BRASIL: EL TERRITORIO COMO FONDO Y TEXTO}

\section{RESUMEN}

El reconocimiento legal de los quilombos en Brasil representa un hito en la visibilidad de las diferencias étnicas y culturales de la sociedad. El mito de la democracia racial borran el dolor de la esclavitud, haciendo lesiones de identidades en los descendentes africanos. Tomando en cuenta la lucha por el reconocimiento, buscase la ampliación de sus derechos, como la educación quilombola. Hay grandes retos, incluso el de cambiar la cultura de la escuela que no atenta para la diversidad étnica brasileña. Eso no significa volver al pasado, más bien, aflorar el presente y relucir la historia y su ascendencia en las experiencias que condujeron la formación de su organización social. Las propuestas educativas oriundas de su etnia y cultura pueden abarcar el contexto y el texto territorial. Los quilombolas traen el territorio que habla a través de la historia oral e permiten escuchar estos significados..

PALABRAS CLAVE

la territorialidade; etnicidad; educación quilombola. 
Uma cultura democrática implica no resgate de uma memória coletiva dentro da experiência histórica da democracia política. É preciso reinventar essa democracia dentro do quadro social da realidade brasileira, que é um quadro de heterogeneidade cultural, de diversidade cultural. Como é que esse saber do livro, do monumento, da bistória do país se articula com um projeto de enraizamento do lugar onde estamos, do que somos, e de como somos e não como deveríamos ser?

SODRÉ, 2002, p. 21

\section{INTRODUÇÃO}

Desde o final do século XX, vem se debatendo acerca da regularização de territórios quilombolas que se insurgiram no cenário rural brasileiro dentro do contexto de modernização territorial empreendido principalmente a partir dos governos militares. Com base na ideologia desenvolvimentista se implantaram grandes projetos técnico-científicos, agropecuários, madeireiras, hidroelétricas, sob a égide de estratégias geopolíticas que tiveram como tema ocupar espaços "vazios”. $\mathrm{Na}$ Amazônia e em outros espaços brasileiros, não só os migrantes, terras indígenas, camponeses e trabalhadores rurais foram impactados por esse modelo base da expansão do capital monopolista que tinha como pressuposto a integração territorial. Nesse processo também se revelaram formas de acesso à terra, cujas especificidades se assentam em ancestralidades, memórias, territorialidades e formas de uso comum oriundas da escravidão, como as terras quilombolas.

A Constituição Brasileira de 1988 veio reconhecer o direito à titulação dessas comunidades por intermédio das organizações sociais do campo e da cidade, dos movimentos negros, parlamentares e pastorais da terra, dos quais falaremos mais à frente. Não obstante, empreenderam-se discussões sobre quem são e como podem ser entendidos e identificados os "remanescentes de quilombos", questionando-se a definição do conceito no artigo constitucional. No campo da cultura e da identidade, seria preciso pensar sobre as formas de como, no presente, as pessoas se veem e como elas se identificam e de que aquele entendimento dificulta a análise ao pressupor o quilombo como reminiscência do passado. Tendo em vista essa questão posta em debate, por meio do decreto n. 4.887/2003 tornou-se possível a autodeterminação dos próprios membros das comunidades. Se esse mecanismo apareceu como meio democrático de reconhecimento da identidade, também se deparou com outros obstáculos, entre eles o consenso dos grupos e a reação conservadora de agentes econômicos e políticos que historicamente se contrapõem a toda forma de acesso democrático à terra.

Liga-se a esse processo o fato de que a educação brasileira, historicamente, alijou grande parcela da sociedade de um ensino público, gratuito e de qualidade, 
verificando-se ainda que o afrodescendente compõe, até os dias atuais, o maior número de estudantes que se evade da escolarização completa. ${ }^{1}$

A proposta deste trabalho é analisar o significado e as formas que a educação pode assumir no contexto da singularidade territorial quilombola. A escola brasileira permitiria a realização de potências transformadoras na escola brasileira e o reconhecimento da multiculturalidade no seu interior? A educação e o acesso à escolarização são direitos acalentados entre os afro-brasileiros, desde a escravidão, tornando-se ponto central para alcançarem a emancipação. Nesse sentido, a questão suscita a pensar processos educacionais que construam ações de reconhecimento (Honneth, 2003) dos sujeitos que protagonizam a vida nos territórios quilombolas, buscando pedagogias significativas que articulem, como diz Moniz Bandeira, o enraizamento, a revelação do que somos e de como somos e não como deveríamos ser no horizonte da educação para a libertação.

A luta pelo reconhecimento refere-se, segundo Honneth (idem), aos processos de reação ao desrespeito e às formas de marginalização e desconsideração dos direitos dos indivíduos de ser e existir em suas mais variadas formas. Os prejuízos causados passam pelos sentidos morais e jurídicos, pois se trata de pensar sobre a degradação da pessoa que pertence a um grupo mais amplo e as feridas causadas em sua autoestima, honra ou dignidade, conforme nos esclarece Melo (2014, p. 23):

E a chave para Honneth analisar os conflitos sociais é a tipologia das formas de reconhecimento e as correspondentes formas de desrespeito [...]. O que importa mostrar é a lógica dos conflitos que se originam de uma experiência social de desrespeito, de uma violação da identidade pessoal ou coletiva, capaz de conduzir a uma mobilização política para restabelecer as relações de reconhecimento mútuo ou expandi-las a outro patamar.

As lutas na contemporaneidade exigem reparações e o reconhecimento social e jurídico de garantia à inserção social dos grupos e indivíduos privados de direitos. A multiplicidade de organizações sociais no Brasil pode ser observada nos movimentos do campo e da cidade. Almeida (2004, p. 166) aponta para as reivindicações advindas de grupos diversos que se têm autodeclarado culturalmente e desenvolvido organizações de movimentos políticos nos territórios nos quais desenvolvem sua vida e seu trabalho. $\mathrm{Na}$ região amazônica, o autor identificou múltiplas formas associativas cujo caráter identificativo se assenta sobre critérios étnicos diferenciados e coletivos, tais como: Conselho Nacional dos Seringueiros (CNS), Movimento Interestadual das Quebradeiras de Coco Babaçu (MIQCB), Coordenação Nacional das Comunidades Quilombolas (CONAQ), Movimento dos Fundos de Pasto, entre outras.

1 Segundo o estudo Acesso ao ensino superior no Brasil: equidade e desigualdade social (Andrade, 2002), mais de 50\% dos jovens sequer atingiu o nível médio e, destes, praticamente a metade não concluiu ao menos o ensino básico. Nesse quadro, os jovens que se autodeclararam não brancos apresentam níveis inferiores de escolaridade em relação aos brancos. 
Tais movimentos ultrapassam as fronteiras político-administrativas, diferem-se das organizações sindicais que se enfraqueceram e fogem ao sentido estrito da política clientelística tradicional. A tradição tem sido o significado característico da ocupação permanente de terras. Esse sentido é reafirmado pelos movimentos sociais e pelo Brasil ao ratificar a Convenção 169 da Organização Internacional do Trabalho (OIT), de junho de 1989 (Almeida, 2008). ${ }^{2}$ Dessa forma, presencia-se uma multiplicidade de identificações que se distinguem da categoria política de camponês. Na medida em que as populações se organizam em associações movidas pelo sentido próprio do cotidiano, constrói-se um emaranhado de articulações políticas, de construções coletivas, confirmando "práticas rotineiras no uso da terra" (Almeida, 2004, p. 169).

A afirmação dos sujeitos tem se dado em virtude de suas próprias demandas sociais e territoriais, diferenciando-se dos marcos governamentais e das estratégias de planejamento, que muitas vezes desconsideram as singularidades nas políticas públicas. Tais organizações acionam autonomamente os poderes públicos para o reconhecimento de seus modos de vida e das necessidades para a reprodução dos grupos que constroem, assim, uma narrativa de si, de sua história, da coletividade e da relação com os territórios de vida.

Conforme Moura (1981), onde houve escravidão existiu resistência, caracterizando o quilombo como um dos movimentos mais fortes de reação à escravidão. A presença de quilombolas no Brasil contemporâneo, contudo, não se resgata como ruínas do passado pela pesquisa arqueológica, pois mesmo aqueles agrupamentos sempre abarcaram indígenas, camponeses e outros sujeitos, o que torna a questão complexa. Ao mesmo tempo, novas pesquisas trouxeram a formação de quilombos não somente a partir de fugas e insurreições, mas de diversos outros contextos, como heranças de terras de antigos senhores, abandono das plantações e das terras em razão da decadência econômica ou pela compra de alforria e manutenção de um território próprio e a produção autônoma. ${ }^{3}$ Porém, após a abolição iniciou-se uma trajetória de exclusão social e invisibilidade, que na prática negou direitos aos afrodescendentes e desconheceu os territórios quilombolas na estrutura agrária brasileira. Além de não haver políticas reparatórias ou indenizatórias pelos três séculos de exploração escravista, por meio da construção ideológica do branqueamento vivenciou-se um imaginário de harmonia e democracia racial que buscou apagar da memória social as lutas e as dores da escravidão.

Esses processos envolvem a discussão entre os que buscam atuar na escola, em movimentos sociais ou na universidade, para a construção de processos educacionais que visem à formação de sujeitos dentro de outros paradigmas. Há interesse

2 O Brasil ratificou a Convenção 169 da OIT, de junho de 1989, cujo artigo 14 assevera: "Dever-se-á reconhecer aos povos interessados os direitos de propriedade e de posse sobre as terras que tradicionalmente ocupam".

3 Segundo Almeida (1989), originaram-se ainda na escravidão, nas fugas, formando quilombos com doações de terras pelos antigos senhores, na decadência da grande lavoura, e correspondem ainda a áreas de alforriados e prestação de serviços militares ao Estado, como ocorreu no Maranhão (Balaiada - 1838-1841). 
por parte das lideranças quilombolas em projetos de escolarização de adultos em seus sítios de moradias, sobretudo quando estão próximos de instituições de ensino superior e escolares da educação básica. Como as crianças moradoras de quilombos, muitas delas, já se encontram nas escolas da região, a preocupação tem sido a invisibilidade no espaço escolar e nos currículos trabalhados por seus professores de temas relacionados à cultura quilombola e afro-brasileira. Nesse sentido, há a necessidade de salvaguardar e reforçar a identidade cultural em ambientes escolares que, explicitamente ou não, podem vir a manifestar formas de preconceito e racismo e repensar processos educacionais que abarquem as comunidades quilombolas como elemento central de seus projetos.

\section{O RECONHECIMENTO DO QUILOMBO NO BRASIL}

$\mathrm{O}$ (re)aparecimento do quilombo, na segunda metade do século XX, constitui-se processo histórico de grande relevância, pois coloca em xeque tanto o próprio conceito na historiografia quanto os movimentos sociais, pondo em relevo a diversidade étnica brasileira. Por mais de um século considerou-se o quilombo parte do período colonial, criando-se uma ideia de que essas lutas findaram após a abolição. Desde a década de 1970, iniciam-se alguns estudos abordando comunidades rurais que apresentavam a particularidade de serem negras. $\mathrm{Na}$ década de 1980, na Universidade de São Paulo (USP), novas pesquisas se pautam na questão da etnicidade, envolvendo identificações culturais de origens étnicas e raciais de comunidades negras que tinham a particularidade se serem camponesas (Arruti, 2006). Segundo o autor:

Porém, a lógica interna a esses debates seria alterada a partir de 1988 e, especificamente, a partir de 1995, pelo impacto do "artigo 68", que se fez sentir na mobilização de ONGs, aparelhos de Estado, profissionais de Estado, profissionais de Justiça, entre outros, nem sempre em perfeito acordo, mesmo quando imbuídos de uma perspectiva pública comum. O campo de estudos sobre a população negra deveria, então, responder a novas demandas, diretamente formuladas pelo movimento social, o que gerou uma espécie de aliança força$d a$ entre perspectivas até então apartadas, impondo aos estudos etnográficos sobre comunidades rurais negras a literatura histórica sobre quilombos e vice-versa, enquanto o que antes existia era uma oposição explícita entre eles. (idem, p. 64-65)

Essa perspectiva teórica e jurídica ampliou-se com a redemocratização brasileira, quando houve um novo debate a respeito da reforma agrária, tendo em vista diversos conflitos fundiários. Porém a complexidade no campo brasileiro mostrava-se maior, revelando formas de ocupação da terra que sobressaíam aos princípios norteadores para o reconhecimento dos estabelecimentos e da dominialidade existentes. O que aparecia como diferente do conjunto dos movimentos sociais tratou-se como ocupações especiais pelo cadastro de glebas do Ministério Extraordinário para o Desenvolvimento e a Reforma Agrária/ Instituto Nacional de Colonização e Reforma Agrária (MIRAD-INCRA). Eram terras de uso comum, que não cor- 
respondiam às formas usualmente empregadas no campo brasileiro, como as terras de preto, terras de santo e terras de indio (Almeida, 2002, p. 46).

Durante os trabalhos da Constituinte, movimentos sociais, pastorais da terra, movimentos negros e parlamentares estiveram presentes e exerceram pressão para o reconhecimento jurídico das terras de quilombos, resultando na aprovação do artigo 68 do Ato das Disposições Constitucionais Transitórias da Constituição de $1988 .{ }^{4}$ A consideração da especificidade de ocupação dessas terras é histórica e foi possível por meio da materialização da história e cultura vinculadas ao território. Além disso, foram incluídos os artigos 215 e $216, \S 5^{\circ}, 5$ que dispõem sobre o tombamento das terras, bem como todos os documentos referentes à sua história no Brasil.

Abriu-se, então, um debate conceitual sobre a consideração de remanescentes de quilombos uma vez que parecia tratar-se da história do passado. Segundo Ratts (2010a), o questionamento ocorre também no âmbito acadêmico e apresenta-se como problemática às narrativas dos sujeitos em questão:

As comunidades negras rurais estabelecem alianças com variados segmentos locais, regionais e nacionais e essa outra face da diversidade rural brasileira deve ser considerada por aqueles que estão envolvidos com essa mobilização crescente. Seja como "remanescentes de quilombo", "quilombolas", "mocambeiros", etc., as representações dos agrupamentos negros rurais, com base na memória, no parentesco, no lugar que construíram, vêm "reaparecendo" em contextos que lhes são geralmente adversos. (idem, p. 318-319)

Tratava-se de delimitar no campo jurídico o processo pelo qual se definiriam as comunidades, no sentido de que o conceito se remetia ao que se pensava terem sido as revoltas contra a escravidão no período colonial, quando o quilombo foi definido pelo Conselho Ultramarino, em 1741, como "toda habitação de negros fugidos, que passem de cinco, em parte despovoada, ainda que não tenham ranchos levantados e nem se achem pilóes neles", em resposta aos movimentos que assolavam a colônia (Lara, 1996, p. 87 e 108).

4 A aprovação do artigo 68 do Ato das Disposições Constitucionais Transitórias conferiu o seguinte direito: "Aos remanescentes das comunidades dos quilombos que estejam ocupando suas terras é reconhecido a propriedade definitiva, devendo o Estado emitir-lhes os títulos respectivos".

5 "Artigo 215. O Estado garantirá a todos o pleno exercício dos direitos culturais e acesso às fontes da cultura nacional e apoiará e incentivará a valorização e a difusão das manifestações culturais.

$\S 1^{\mathrm{o}}-\mathrm{O}$ Estado protegerá as manifestações das culturas populares, indígenas e afro-brasileiras, e das de outros grupos participantes do processo civilizatório nacional.

Artigo 216. Constituem patrimônio cultural brasileiro os bens de natureza material e imaterial, tomados individualmente ou em conjunto, portadores de referência à identidade, à ação, à memória dos diferentes grupos formadores da sociedade brasileira, nos quais se incluem:

$\S 5^{\circ}-$ Ficam tombados todos os documentos e os sitios detentores de reminiscências históricas dos antigos quilombos". 
Em 20 de novembro de 2003, foi sancionado o decreto n. $4.887,6$ que veio regulamentar o procedimento para identificação, reconhecimento, delimitação, demarcação e titulação das terras de quilombos. Essa legislação prediz a realização de procedimentos de autodefinição com os elementos que indiquem a trajetória histórica das comunidades, sua relação com a terra e presumindo-se a ancestralidade negra. A Fundação Cultural Palmares ${ }^{7}$ mantém a responsabilidade de certificar os grupos. O decreto explicitou também a necessidade de relatórios e do laudo pericial para identificação dos grupos, depositando a titulação a cargo do INCRA.

O diferencial que passa a vigorar é que os próprios sujeitos definem sua identidade a partir da organização social e pelos critérios construídos no seu modo de vida, concernentes às características de uso dos recursos e dos laços comuns aos seus integrantes que, tradicionalmente, estabeleceram.

\section{TERRA, ETNIA E TERRITÓRIO}

A concepção de diversidade cultural atribuída aos grupos sociais no mundo contemporâneo nem sempre revela as especificidades da identificação que estes assumem. Segundo Barth (2005), deve-se questionar de onde e como nasce a cultura, pois ela não está no lugar, mas num fluxo intenso de contatos e vivências existentes nas organizações sociais. Seria possível, assim, asseverar que nenhum grupo social encontra-se em isolamento geográfico ou se constitui numa unidade cultural homogênea. Trata-se, sim, de uma dinâmica mais ampla envolvendo confrontos, conflitos, negociações e silenciamentos. Estes são aplicados por forças de controle social, que ora reconhecem a diversidade cultural, ora podem mesmo reforçá-la, conforme as possibilidades de ganhos políticos e interesses territoriais. Nesse sentido, o território é base do poder do Estado, que defende uma comunidade de interesses, mas que apresentam, em seu interior, múltiplas organizações em processo. Conforme Raffestin (1993), a presença de territorialidades fora do projeto estatal, as quais fazem parte das formas de representação social do viver territorial, resulta da luta pela apropriação dos bens territoriais necessários à sobrevivência. Os grupos contrariam, assim, as formas de ocupação existentes, uma vez que a terra-território é coletiva.

6 Aponta o artigo 2o: Consideram-se remanescentes das comunidades dos quilombos, para os fins deste Decreto, os grupos étnico-raciais, segundo critérios de autoatribuição, com trajetória histórica própria, dotados de relações territoriais específicas, com presunção de ancestralidade negra relacionada com a resistência à opressão histórica sofrida.

$\$ 1^{\circ}$ Para os fins deste Decreto, a caracterização dos remanescentes das comunidades dos quilombos será testada mediante autodefinição da própria comunidade.

$\$ 2^{\circ}$ São terras ocupadas por remanescentes das comunidades dos quilombos as utilizadas para a garantia de sua reprodução física, social, econômica e cultural.

$\$ 3^{\circ}$ Para a medição e demarcação das terras, serão levados em consideração critérios de territorialidade indicados pelos remanescentes das comunidades dos quilombos, sendo facultado à comunidade interessada apresentar as peças técnicas para a instrução procedimental.

7 A Fundação Cultural Palmares é uma entidade pública brasileira vinculada ao Ministério da Cultura (MEC), instituída pela lei federal n. 7.668, de 22 de agosto de 1988. 
A luta pela terra no Brasil envolve uma trama de relações sociais, culturais e políticas; nasce das determinações objetivas impostas historicamente à produção camponesa. $\mathrm{O}$ que se assiste agora é a mobilização de uma pluralidade de sujeitos valendo-se de elementos culturais e étnicos que se expressam nos contextos históricos do desenvolvimento da modernização brasileira, infligindo-lhes ameaças de expulsão e morte física ou cultural. Por isso a organização mais estruturada mostra a existência de condições subjetivas a cada um dos grupos que os desafiam à inserção no movimento social.

A memória ganha contorno no processo de luta, regulando a identidade desses grupos pelos vínculos entre o presente e o passado, reforçando a organização social (Bosi, 2002). A recordação é elaborada com base nas necessidades atuais, pelo temor à perda definitiva da terra.

Esse processo pressupõe a construção da memória coletiva, pelo que diz Halbwachs (2006, p. 109):

[...] A memória coletiva é um painel de semelhanças, é natural que se convença de que o grupo permaneça, que tenha permanecido o mesmo, por que ela fixa sua atenção sobre o grupo e o que mudou foram as relações ou contatos do grupo com os outros. Como o grupo é sempre o mesmo, as mudanças devem ser aparentes: as mudanças, ou seja, os acontecimentos que ocorreram no grupo, se resolvem em semelhanças, pois parecem ter como papel desenvolver sob diversos aspectos um conteúdo idêntico, os diversos traços essenciais do próprio grupo.

Assim, a memória coletiva articula os quilombolas em torno da terra, da etnia e do território. A permanência dessas comunidades ocorre sob as tensões que reforçam o modo de vida que (re)construíram. Nesse sentido, muitos jovens partiram para as cidades em busca de melhores condições de vida e depois retornaram, percebendo que esse território é base para a sua identidade e que em outros lugares experimentaram a fragmentação e a exclusão.

Esse fluxo de sujeitos que vivenciam experiências diversas remete a pensar sobre as questões de continuidade e descontinuidade cultural e étnica, uma vez que a identidade não é sempre consensual no processo de organização social, mas, com efeito, no processo de mobilização pode aparentar aos olhos externos como homogênea.

Tais posições e experiências influenciam a relação entre cultura e etnicidade, pois tende-se a avaliar a diversidade cultural como discernível no mundo, mediante a premissa de certa padronização em cada uma das unidades sociais, embora existam as descontinuidades, mas também continuidades.

A cultura, para Barth (2005), é entendida como parte das experiências que os indivíduos passam pelo mundo, o que permite uma variedade de aprendizados que possibilitam alterar, reforçar ou gerar as identidades étnicas, construindo uma multiplicidade de agrupamentos. Essa dinâmica remete ao fato de que as culturas estão sempre sendo impactadas, que fazem parte de um fluxo, não podendo ser 
pensadas em termos fixos da tradição, do passado ou de um lugar, mas dos arranjos presentes em que elas são geradas.

$\mathrm{O}$ uso comum da terra quilombola, engendrado na ancestralidade, e a base física e imaginária desses grupos têm um papel fundamental nessa perspectiva teórica. Seu valor funda-se na satisfação de suas necessidades mútuas, que incluem o simbólico, as tradições e as sobrevivências culturais. É nesse sentido que território, cultura e etnicidade se mesclam, assegurando-lhes a continuidade.

As terras de quilombos distribuem-se em praticamente todos os estados brasileiros e, segundo a Fundação Cultural Palmares, o país apresentava 2.408 comunidades certificadas até outubro de 2013. Apesar dessa soma, segundo o INCRA, apenas 139 títulos foram emitidos em favor de 207 dessas comunidades, representando apenas 8,6\% das comunidades certificadas (Instituto de Pesquisa Econômica Aplicada - IPEA, 2015).

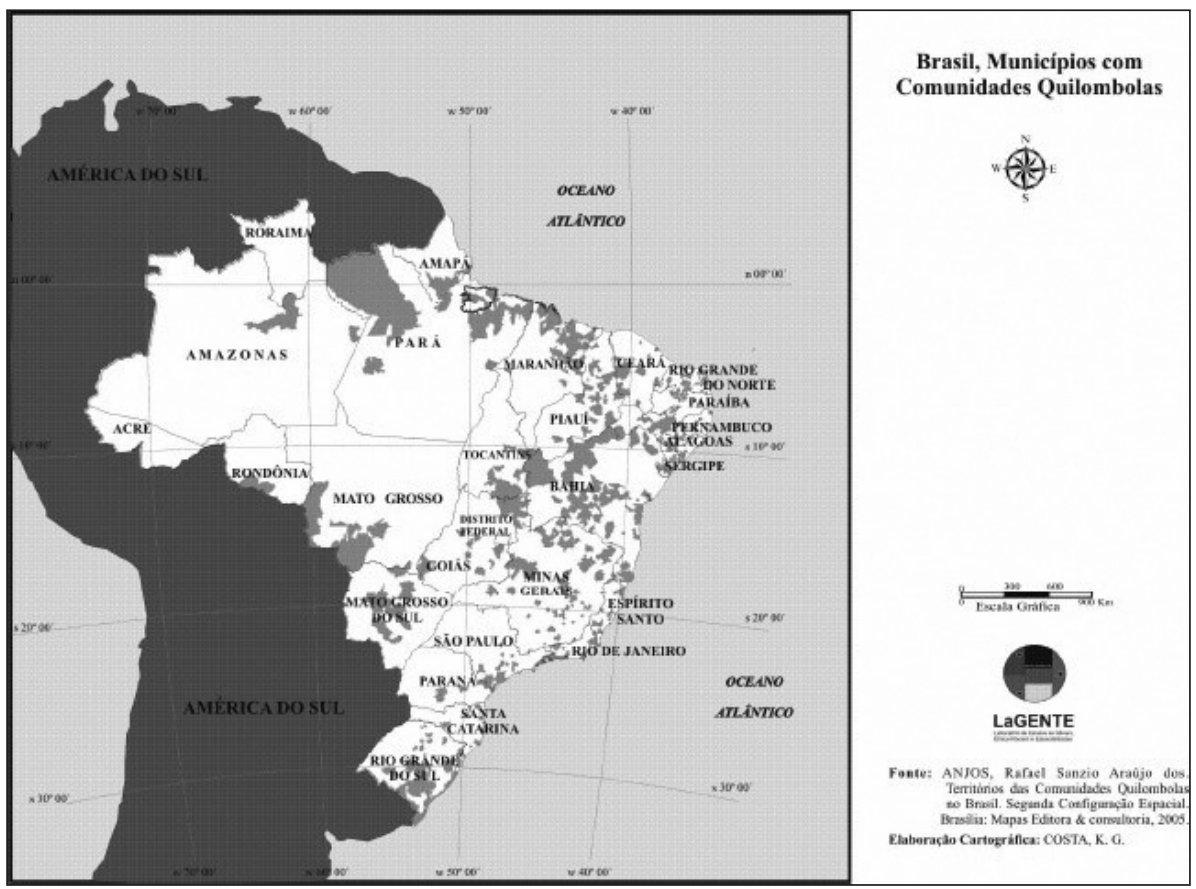

Figura 1 - Brasil - Municípios com comunidades quilombolas, 2005.

Fonte: Ratts (2010b, p. 131).

Na Figura 1, que traz a segunda reconfiguração cartográfica dessa espacialização, verifica-se crescente aumento de certificações, decorrentes de movimentos 
sociais audeclaratórios e tensões envolvendo os territórios. Contudo o processo de titulação tem sido longo, pois a definição dos limites territoriais é bastante complexa, tendo em vista os processos históricos e políticos envolvidos. Há sobreposição de títulos de propriedade, demandando ações individuais na justiça federal,incidência de parques e reservas ambientais, dificultando as demarcações, além da organização de associações de moradores para a destinação do título. O mapa expressa, ainda, a concentração desses territórios nas regiões Norte e Nordeste, onde prevalece número elevado de regularizações. O Pará, por exemplo, concluiu 20 titulações, entre 2006 e 2010. Em 2014, entre as 154 terras tituladas, aparecem as primeiras em Santa Catarina, Pernambuco e Rio Grande do Norte. ${ }^{8}$

\section{OS DESAFIOS DA EDUCAÇÃO QUILOMBOLA NO BRASIL}

No Brasil, o processo de conquista de direitos é ainda presente e a luta por justiça e educação remete à história da formação social brasileira. No contexto da primeira Constituição da República, o cidadão que se tinha ainda era dependente da "política do favor". Segundo Carvalho (2006), o país nasceu sob o aniquilamento de povos, e isso contribuiu para que, mesmo após ter conquistado a independência, a nação não tornasse claramente definido o objetivo de inserir a cidadania como pressuposto para a sua existência:

[...] os direitos civis beneficiavam a poucos, os direitos políticos a pouquíssimos, dos direitos civis ainda não se falava, pois a assistência social estava a cargo de Igreja e de particulares [...]. (idem, p. 24)

Não havia República de fato, nem cidadãos, tampouco um sentimento de nação, pois a escravidão mesmo quando abolida deixara um legado de desigualdade e exclusão. Um exemplo será a herança do trabalho manual como inferior.

A história da educação brasileira terá como balizadora a formação de uma sociedade dualista, decorrente dos séculos de escravidão e que se desdobra para além desse período. A lógica da escravidão estava em desacordo com as premissas da modernidade, do liberalismo, da liberdade do indivíduo, do domínio sobre seu próprio corpo e da vontade autônoma (Schwarz, 2012). Encontrava-se sob a lógica econômica de base colonial, produtora de matérias primas e agrária exportadoras. A divisão do saber e fazer, da lógica industrialista, da criatividade e da inventividade ficou restrita a um pequeno domínio social.

No Brasil, somente em 1930 foi criado o Ministério da Educação e Saúde e o Conselho Nacional de Educação, organizando o ensino superior. Data de 1931, também, a publicação do Manifesto dos Pioneiros da Educação Nova, ${ }^{9}$ sob a influência do ideário escolanovista, surgido na Europa e nos Estados Unidos (Vidal,

8 Dados disponíveis em: <http://comissaoproindio.blogspot.com.br/2015/02/20-terrasquilombolas-tituladas-em-2014.html >. Acesso em: 20 dez. 2016.

9 O Manifesto reivindicava a direção do movimento de renovação educacional brasileiro, como se mostra em seu próprio título. 
2013). O Manifesto vinha a público no âmago das disputas pela condução das políticas do recém-criado Ministério da Educação e Saúde no Brasil (1930), e seu texto exibia um triplo propósito: efetuava a defesa de princípios gerais que, sob a rubrica de novos ideais de educação, pretendiam modernizar o sistema educativo e a sociedade brasileira; com a publicação do Manifesto apareciam os pioneiros da Educação Nova, descaracterizando as investidas anteriores na arena educacional e, finalmente, o texto se produzia como marco fundador no debate educativo brasileiro.

A criação de uma escola unitária, que aproximasse o mundo do trabalho do mundo da escola, se realizara nesse período. As aspirações para uma melhor formação profissional, técnica e humanista, contudo, foram atendidas por meio de pacotes escolares de curta duração, no ensino noturno, com os exames e o ensino supletivo adaptados para facilitar a escolarização popular, políticas estas muitas vezes de caráter populista.

A escola pública não contemplará uma grande parte da sociedade brasileira e, principalmente, deixa o negro à margem do direito à educação. Por isso, segmentos negros letrados estruturaram um movimento de organização sobretudo a partir da criação da Imprensa Negra. São Paulo e Rio de Janeiro foram os principais centros dessa mobilização dos afro-brasileiros que, desde 1910, buscaram alcançar a cidadania que a abolição não concretizara. No tocante à escolarização, observa-se a ascensão de uma intelectualidade negra que reconhecia no domínio da escrita um meio para adentrar espaços sociais, entendendo que na prática, mesmo tendo garantido o direito dos libertos estudarem, a eles não eram oferecidas as condições necessárias para a escolarização (Machado, 2009). Porém um segmento social negro alcançará níveis de instrução criando as suas próprias escolas. O ensino era oferecido por pessoas escolarizadas, que adentravam a rede pública gratuita, os asilos de órfãos e vagas nas escolas particulares.

Segundo Passos (2010, p. 61-62), cursos noturnos foram criados a partir do Congresso Agrícola do Rio de Janeiro, em 1878, quando ocorreu um amplo debate sobre a educação para livres e libertos no município da Corte, sendo estabelecido que esse processo tivesse validade nacional. Segundo a autora, tal fato provocou a criação de cursos semelhantes em diversas províncias, surgindo ações de instrução primária e profissional de adultos. Porém não significou "que essas experiências tenham se universalizado para escravos e negros livres, pois em outras províncias, como, por exemplo, São Pedro do Rio Grande do Sul, era proibida a presença de escravos e de negros libertos e livres" (idem, p. 62).

A oficialização da educação de jovens e adultos aparece em 1945, segundo campanhas mobilizadoras, que ensejavam a alfabetização - atravessando décadas com o objetivo de superar as elevadas taxas de analfabetismo:

Campanha de Educação de Adolescentes e Adultos - CEAA (1947); o Movimento de Educação de Base - MEB, sistema rádio educativo criado na Conferência Nacional dos Bispos do Brasil com o apoio do Governo Federal (1961), além dos Centros Populares de Cultura - CPP (1963), Movimento de Cultura Popular - MCP e a Campanha Pé no Chão Também se Aprende a Ler. (Manson, 2009, p. 29) 
Conforme Brandão (2002), sobretudo nos anos de 1960 a 1964 floresceram práticas pedagógicas envolvendo nomes, como o de Paulo Freire, que defendiam experiências de educação popular. Tendo o fundamento da cultura como processo histórico, propôs-se uma educação capaz de apreender os sujeitos não como essência dada, mas pelos atos de criação social:

Ser o sujeito da história e ser o agente criador da cultura não são adjetivos qualificadores do homem. São o seu substantivo. Mas não são igualmente a sua essência e, sim, um momento do seu próprio processo dialético de humanização. No espaço de tensão entre a necessidade (as suas limitações como ser da natureza) e a liberdade (o seu poder de transcender ao mundo por atos conscientes de reflexão), o homem realiza um trabalho único que, criando o mundo de cultura e fazendo a história humana, cria a própria trajetória de humanização do homem. (idem, p. 41)

No decorrer desse acontecimento, a universalização da educação e a preocupação com a educação popular será um processo muito lento e longo, continuando como uma dívida social até os dias atuais. Até a década de 1940, ainda havia muitos analfabetos no Brasil, em torno de 56\%, chegando ao ano de 2010 com 9,6\% (IBGE, 2012). Essa diminuição, embora represente avanços à universalização da educação, revela contrastes entre a alfabetização efetiva e os resultados do processo que expressam o analfabetismo funcional. ${ }^{10}$

O espaço escolar reflete a sociedade e suas contradições, sendo palco de conflitos e desigualdades múltiplas e sobrepostas. Contudo, priorizar e potencializar as possibilidades existentes tem como objetivo desenvolver mecanismos educativos no horizonte da emancipação, conforme Paulo Freire, para quem a escola é vida:

[...] compreensão crítica do ato de ler, que não se esgota na decodificação pura da palavra escrita ou da linguagem escrita, mas que se antecipa e se alonga na inteligência do mundo. (Freire, 2006, p. 11)

A escola não pode mais permanecer atuando perante os seus alunos, ideologicamente, como se todos fossem iguais, reproduzindo um ideal abstrato dos sujeitos, ao mesmo tempo transmitindo uma neutralidade em seus conteúdos curriculares. Um dos avanços nesse sentido ocorre no âmbito das políticas afirmativas, com a aprovação da resolução n. 8, de 20 de novembro de 2012, que definiu as Diretrizes Curriculares Nacionais para a Educação Escolar Quilombola na Educação Básica (doravante DCN):

10 Para calcular o analfabetismo funcional, o Instituto Brasileiro de Geografia e Estatística (IBGE) utiliza o número de pessoas maiores de 15 anos e com menos de quatro anos de estudo. Segundo a definição da Organização das Nações Unidas para a Educação, a Ciência e a Cultura (UNESCO), funcionalmente alfabetizada é a pessoa que pode participar de todas as atividades em que a alfabetização é necessária para o funcionamento efetivo do seu grupo e comunidade e também para lhe permitir continuar a utilizar a leitura, a escrita e o cálculo para seu próprio desenvolvimento e da comunidade. 
Uma proposta de educação quilombola necessita fazer parte da construção de um currículo escolar aberto, flexível e de caráter interdisciplinar, elaborado de modo a articular o conhecimento escolar e os conhecimentos construídos pelas comunidades quilombolas. Isso significa que o próprio projeto político-pedagógico da instituição escolar ou das organizações educacionais deve considerar as especificidades históricas, culturais, sociais, políticas, econômicas e identitárias das comunidades quilombolas, o que implica numa gestão democrática da escola que envolve a participação das comunidades escolares, sociais e quilombolas e suas lideranças. Por sua vez, a permanência deve ser garantida por meio da alimentação escolar e a inserção da realidade quilombola em todo o material didático e de apoio pedagógico produzido em articulação com a comunidade, sistemas de ensino e instituições de Educação Superior. (Brasil, 2012, p. 26)

A política pública representa avanços significativos na história da educação brasileira, notadamente na forma como se inseriram os afrodescendentes não somente na escola, mas na própria sociedade que, desde o final da escravidão, tentou definir um lugar de ausência e esquecimento desse segmento. Rumando ao contrário do trajeto de subalternidade e submissão às hierarquias que tanto marcam a formação social do país, o projeto de uma educação diferenciada para as comunidades etnicamente declaradas acaba por transformar as feições sociais pelo reconhecimento amplo das identidades que fazem parte da diversidade cultural e étnica no país. Segundo Miranda (2012, p. 374):

A implantação da modalidade de educação quilombola insere-se no conjunto mais amplo de desestabilização de estigmas que definiram, ao longo de nossa história, a inserção subalterna da população negra na sociedade e, consequentemente, no sistema escolar.

Os desafios postos para a educação escolar destinada aos estudantes quilombolas são amplos e antagônicos, pois o reconhecimento da especificidade é franco a partir da própria criação das DCN, da atenção que tem sido levada às escolas quilombolas ${ }^{11} \mathrm{e}$ às que não se encontram nesses territórios, mas que buscam atender as crianças das comunidades. Recursos financeiros, material didático específico e o incentivo do Programa Nacional de Alimentação Escolar (PNAE) ${ }^{12}$ revelam avanços. Contudo são muitas as inseguranças presentes na educação quilombola, envolvendo as condições dos estabelecimentos escolares, o uso de recursos didáticos apropriados e a formação docente.

11 Conforme artigo $1^{\circ}$, inciso IV, da resolução n. 8/2012 do CNE: "As escolas quilombolas são reconhecidas pelos órgãos públicos e se localizam nas comunidades devidamente certificadas pela FCP”.

12 A resolução n. 26, de 17 de junho de 2013, dispõe sobre o atendimento da alimentação escolar aos alunos da educação básica no Programa Nacional de Alimentação Escolar (PNAE). 
Segundo levantamento do Instituto Nacional de Estudos e Pesquisas Educacionais Anísio Teixeira (INEP) ${ }^{13}$ as escolas quilombolas (2.235 estabelecimentos no país), representam apenas 1,2\% do total de estabelecimentos de educação básica no país e apenas $0,45 \%$ das matrículas nesse nível. Concentram-se na região Nordeste acompanhando a porcentagem de comunidades certificadas nessa região $(63,7 \%)$ e em estabelecimentos municipais em geral responsáveis pelas etapas iniciais da educação básica. Apenas 135 estabelecimentos (6\%) estão localizados na área urbana, concentrando $21,2 \%$ das matrículas. Vê-se que há estabelecimentos atendendo a estudantes quilombolas fora de seus territórios, muitos em áreas urbanas, o que demanda uma investigação com maior acuidade a respeito da procedência do aluno.

O documento Educação escolar quilombola no Censo da Educação Básica (IPEA, 2015) estima que, além dos estabelecimentos declarados em áreas remanescentes de quilombos, outros 552 devem receber estudantes oriundos dessas áreas, tendo em vista a utilização de material específico para diversidade sociocultural quilombola, totalizando-se 2.787 estabelecimentos, de acordo com a classificação das DCN para a educação escolar quilombola. Uma das dificuldades para análise dessa ação, segundo a autora do documento, Tatiana Dias Silva, é a não inclusão da residência em territórios quilombolas (ou procedência desses territórios) no formulário de pesquisa dirigido ao aluno.

Concorda-se com a hipótese de que esse item pode estar relacionado a existirem estabelecimentos em áreas quilombolas que não se identificaram como tal e ainda outros fora de área quilombola que recebem estudantes e não utilizam material específico, pois menos da metade das escolas situadas em áreas remanescentes de quilombos informam utilizar esse tipo de material didático.

As condições de funcionamento das escolas quilombolas analisadas por Miranda (2012) em comparação com o documento do IPEA revelam similaridades, pois persistem indicadores mostrando precariedade no atendimento aos estudantes, como segue: a maioria dos estabelecimentos é de pequeno porte, com até duas salas de aula $(57,3 \%)$, prevalência que se repete nas regiões Norte $(64,7 \%)$ e Nordeste $(60,3 \%)$. Apenas $15,3 \%$ dos estabelecimentos têm mais de seis salas, enquanto no total da educação básica 51,5\% têm esse mesmo porte (e 22\% contam com mais de dez salas). Quanto ao local, estão em prédio próprio $88,3 \%$. Algumas funcionam em templos ou igrejas (27); salas de outras escolas (52); ou na casa do professor (18), em números absolutos (Dias, 2015, p. 21). Há 157 escolas que funcionam em local ou abrigo destinado à guarda ou ao depósito de materiais.

Verifica-se a ausência de acesso a qualquer modalidade de esgoto sanitário ou energia elétrica, comum à maioria das escolas rurais no país. $\mathrm{O}$ recurso mais disponível é o laboratório de informática, embora esteja presente em apenas 22,6\% dos estabelecimentos (estrutura presente em $44,6 \%$ dos estabelecimentos da educação básica) e faltam quadras de esportes.

13 Censo Escolar da Educação Básica 2013, promovido pelo INEP, que a partir de 2004 inclui a declaração da presença de "escolas em áreas remanescentes de quilombos" (Dias, 2015, p. 13). 
O documento acrescenta que, dos estabelecimentos em áreas quilombolas, apenas 783 informaram utilizar materiais específicos (35\% do total) e mostra o relatório da Secretaria de Políticas de Promoção da Igualdade Racial (SEPPIR) ${ }^{14}$ de 2013, indicando que cada uma das 1.912 escolas localizadas nas comunidades remanescentes de quilombos recebeu no exercício de 2009 materiais didáticos: $A$ cor da cultura e, em 2010, o Kit Quilombola.

Quanto à formação docente, existem 13.196 funções docentes na educação básica em áreas quilombolas, indicando a concentração de 63,4\% no Nordeste; em geral, pouco mais de $50 \%$ dos professores que atuam nessa modalidade, no país, têm vínculo efetivo. Dos professores, 48,3\% apresentam o nível superior, mas há ainda uma quantidade considerável que leciona apenas com ensino fundamental, médio e até com o fundamental incompleto. Nesse sentido, percebe-se a insuficiência da formação dos professores na área rural, onde estão mais de $90 \%$ dos estabelecimentos escolares quilombolas e $78,8 \%$ dessas matrículas, o que remete a processos mais longos de escolarização e enraizamento dos afrodescendentes.

\section{DAS SEPARAÇÕES, AUSÊNCIAS E PRESENÇAS}

O enraizamento é talvez a necessidade mais importante e mais desconbecida da alma humana e uma das mais difíceis de definir.

Weill, 1996 apud Bosi, 2002, p. 16

As raízes humanas, na perspectiva de Weill, são centrais para existir e ser, tema fundamental quando se remete ao processo de educação, que na modernidade tornou o espaço escolar o lócus de concretização formativa e do alcance das realizações sociais. Mas, se de um lado a escola promove a socialização, ela também nos afasta das raízes à medida que se liga à universalidade enquanto as particularidades se apagam nos modelos educacionais tradicionais. Nesse sentido, seria possível pensar outro trajeto que guardasse proximidade com os sujeitos? No Brasil, as comunidades quilombolas não deixaram de construir saberes e práticas que moldaram a sua própria vida, aprendendo a cada encontro com o Outro os jogos de poder e a importância de estratégias que lhes permitissem lutar pela existência e serem sujeitos da organização social. Nesse sentido, como a proposta de uma educação diferenciada possibilitaria a narrativa própria desses grupos e a preservação da identidade?

A formulação de uma proposta pedagógica para a educação quilombola certamente carece de pesquisas que envolvam aqueles saberes comunitários e um intercâmbio de conhecimentos entre diversas áreas. A interdisciplinaridade torna-se necessária para a abertura de diálogos entre sociologia, história, geografia, antropologia e outras ciências que venham a contribuir com a elaboração de um currículo pertinente a essa realidade. Essa possibilidade, no atual momento, encontra limites nos diversos fatores dados pela própria cultura institucional e na organização das práticas pedagógicas nos cursos de formação de professores. Segundo Giroux (1997),

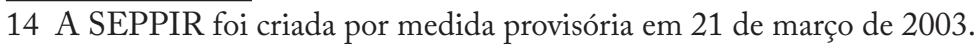


o sistema escolar falha em reconhecer a relação entre a escolarização e a sociedade mais ampla; para o autor, não seria suficiente apenas a mudança do currículo, pois a manutenção de diversos problemas, tais como a preparação inadequada dos professores, materiais descontextualizados aos estudantes, e a própria cultura escolar, com seus espaços fechados, regras e disciplinamento, reforçam, na verdade, a permanência da estrutura social hierárquica vigente.

No entanto, se o escopo for modificarem-se as práticas didáticas mediante a implantação de políticas e a reorganização dos processos de trabalho, não se pode subestimar a questão pedagógica. Caberia, assim, aproveitar as oportunidades de mudança surgidas pelas conquistas atuais, buscando constituir novos sujeitos-agentes ético-políticos.

Para esse fim, propõe-se pensar a educação quilombola com base nos contextos de uso do território, da etnicidade e da memória presentes nas narrativas dos sujeitos no intuito de construir metodologias que proporcionem aprendizagens tendo como ponto de partida elementos referentes às realidades locais das comunidades. Nesse sentido, romper com uma história longa de alienação e exclusão étnica e racial que se inaugura com a formação da sociedade brasileira.

Já se disse que a República e os liberais contrastavam com a realidade de uma nação recém-saída de séculos de escravidão. $\mathrm{Na}$ verdade, uma vertente pessimista de interpretação, em meados do século XIX, representará o país como um "exemplo de nação degenerada de raças mistas" (Schwarcz, 1993). As teorias raciais desse momento condenavam o povo brasileiro à decadência, denunciando a inviabilidade de uma nação composta de raças mistas, o que implicaria na formação social baseada no atraso em razão de sua composição étnica. Sob a influência das ideias evolucionistas e darwinistas formulou-se um pensamento original que colocava a mestiçagem como degeneração, mas como a possível saída para o passado que se pretendia esquecer e uma solução viável para a formação da nação brasileira, lançando-se, então, mão de uma teoria própria que vislumbrava o branqueamento em longo prazo. Essa perspectiva teve repercussões dentro e fora do Brasil com a difusão do mito da democracia racial, que posteriormente foi questionada por intelectuais da Escola de Sociologia Paulista, pelos estudos patrocinados pela UNESCO e por Clóvis Moura (Bandeira, 1988), mas manteve-se como categoria nativa (Guimarães, 2003), tornando-se um valor para os brasileiros tanto a miscigenação quanto a ideia de relações harmônicas.

Essa ideologia, contudo, tem sido cada vez mais demolida não só no meio acadêmico, mas também pelas relações sociais, que tornaram mais explícito o preconceito racial nas últimas décadas, no momento em que as políticas afirmativas, tais como reserva de vagas, de cotas, e as propostas de educação quilombola, são aprovadas.

A história do afrodescendente tem um percurso de ausência e de presença na sociedade brasileira à medida que a dinâmica racial e social se construiu, negando a sua presença e fragmentando-o social e culturalmente. No jogo de representações sociais, pratica-se o racismo conforme a gradação da cor da pele, tornando a identidade uma questão complexa entre ser ou não ser negro, ser mestiço ou ser branco. As representações não são, segundo Lefebvre (1983), necessariamente o mesmo 
que ideologia, pois a vida sem representação seria impossível - representações são formas de comunicar e reelaborar o mundo, aproximações da realidade que, no entanto, não podem substituir o mundo vivido: "É justamente quando o vivido é substituído pelo concebido que a representação se torna ideologia” (Serpa, 2014, p. 487). Ou seja, é quando as estratégias racionalizadoras do espaço e do cotidiano se apropriam das práticas sociais e constroem separações em todas as instâncias da sociedade, como é a do vivido.

As separações se aprofundam no mundo da globalização, assim como os obstáculos à realização humana tornam-se intensos, segundo a teoria crítica. Nesse sentido, a análise de uma nova fase de desenvolvimento do capitalismo indica que os sujeitos são imersos em uma sociedade de signos cada vez mais desconhecidos. No pós-Segunda Guerra Mundial (1939-1945), os modos de opressão atuam de maneiras diferentes à medida que a racionalidade sistêmica passa a operar de forma mais totalizante. $\mathrm{O}$ vivido como parte da estrutura social mais próxima dos indivíduos, da cultura e do lugar vai sendo também colonizado e são impostos os ditames da racionalidade produtiva e burocrática, levando ao estranhamento.

As terras de quilombos vivenciam processos de interferências mais amplas em seu cotidiano, como declarou Dona Maria Antônia, moradora da comunidade quilombola de Pilões, localizada no Vale do Ribeira, região Sudoeste de São Paulo:

O governo não deixa roçar, plantar a restinga no mato... A gente não carecia comprar as coisas do jeito que e não deixa roçar, plantar a restinga no mato... A gente não carecia comprar as coisas do jeito que estão caras... Planta lá no sertão escondido e às vezes paga multa, plantam arroz, milho, mandioca, banana... Só pode plantar perto de casa, senão tem que plantar escondido... O filho meu fez uma roça: arroz, milho, mandioca, batata, couve... agora o mato cresceu e a terra enfraqueceu e não dá mais... ${ }^{15}$

A concepção de áreas protegidas implantadas no vale do Ribeira baseou-se na ideia de terra vazia e intocada, tendo como principal objetivo preservar áreas de interesse ecológico e de manutenção de ecossistemas (Diegues, 1996, p. 11).

Os quilombos desenvolveram uma relação específica com a natureza, de escravos eles se transformaram em camponeses. O relacionamento com a terra tornou-se fundamental como meio de sobrevivência na sociedade escravista. $\mathrm{Vi}$ ver nos quilombos equivalia a arar e cultivar a terra para dela extrair os recursos necessários à vida e também dela fazer sua moradia e nela reconstruir seu suporte cultural, em uma perspectiva de sobrevivência.

É nesse sentido que a vida cotidiana que se vê ameaçada pode ser o ponto de partida para um projeto de educação quilombola que revele e supere as repre-

15 Entrevista realizada com Dona Maria Antônia, 90 anos, da comunidade quilombola de Pilões, no Vale do Ribeira, sobre as restrições impostas aos moradores que se encontram dentro da Área de Proteção Ambiental da Serra do Mar - São Paulo, 20 jul. 1995 (Carril, 1995). 
sentações e práticas que separam os sujeitos de suas culturas, racionalizando os usos do espaço.

\section{A TÍTULO DE CONCLUSÃO}

\section{TERRITÓRIO E TERRITORIALIDADES - DO CONTEXTO AO TEXTO}

No meio do mato ouvi

A voz de uma escrava a gritar

Se eu não voltar para a minha terra

Prefiro morrer pelas águas do mar

Quem sabe eu morrendo por lá

um dia eu possa encontrar

Aqueles meus velhos amigos

Que por crueldade jogaram no mar

Lê-1ê-1ê-lê-lê-lê-lê-1ê-1ê-1ê-1ê-lê-lê-lê,

Quem sabe meu Deus permitiu e

fizeram quilombo no fundo mar

Lê-lê-lê-lê-lê-lê-lê-lê-lê-lê-lê-lê-lê-lê,

Respeite meus velhos amigos

Que tem um quilombo no fundo do mar ${ }^{16,17}$

Como tradição dos antepassados, conta-se a história por meio de narrativas poéticas do jongo e também por meio de textos. Uma das narrativas está registrada no livro Dona Ifigênia, que é uma homenagem a uma das filhas da herdeira das terras do Cafundó, rememorada pela comunidade por simbolizar uma das pessoas que incentivaram a continuidade das tradições, como a Festa de Santa Cruz, além de resguardar e transmitir a língua cupópia para as novas gerações. Hoje a cupópia ainda é utilizada por alguns moradores do quilombo. Segundo Vogt e Fry (1996, p. 105), Dona Ifigênia e sua irmã, Antônia, "ambas escravas e ambas beneficiadas pela doação das terras do cafundó à sua mãe, Ricarda, permaneceram nas terras após a abolição".

O jongo no quilombo do Cafundó, em Salto de Pirapora/SP, faz o corpo falar de sua história, remeter à comunicação ancestral, da mesma maneira como aparece nos autos do maracatu, dos congos, é também uma função do jongo:

Jongo é uma dança. Aí a gente é um entra e sai de pessoas dentro do grupo, mas é uma das coisas principalmente que as crianças gostam muito, então hoje

16 Música cantada no jongo da Festa de Santa Cruz e de São Benedito no Quilombo Cafundó, em Salto de Pirapora - 8 maio 2014.

17 Música Quilombo no fundo do mar (Carla Gomes). Disponível em: <http://jongobanto. blogspot.com.br/2008/10/toadas.html>. Acesso em: 16 fev. 2017. 
é mais as crianças que estão fazendo do que os adultos, o pessoal mais velho; hoje são mais... as crianças, a gente percebe que é uma coisa que elas gostam muito de fazer ${ }^{18}$

Verifica-se que a comunidade do Cafundó, localizada em Salto de Pirapora/ $\mathrm{SP}$, não tem escolas instaladas, as crianças vão à Barra, no município mesmo de Salto de Pirapora, a uns seis quilômetros de distância. Até 2008, as crianças tinham que caminhar até a pista para pegar o ônibus que as levava até a escola. Quando o ônibus quebrava, elas eram largadas na pista e tinham que ir embora sozinhas. A comunidade se engajou numa luta para alcançar melhorias de transporte e também para trabalhar a própria imagem no município, construída valendo-se de histórias preconceituosas sobre o Cafundó. Estabeleceu-se uma espécie de isolamento do quilombo no município de Salto de Pirapora, que só recentemente tem se modificado com a visita de escolas municipais, o que se tornou importante no processo de consideração da alteridade.

Identificar os diversos modos de vida no território, criar a percepção das formas de uso dos recursos, da etnicidade e da memória deve integrar o processo educacional. Está se falando do território como um contexto a ser interpretado, conforme entrevista feita com Milton Santos (1998):

[...] é a primeira vez que a divisão do trabalho é programada, nunca foi antes. Isso é um problema. Então, quando a gente faz falar o território, que é um trabalho que creio que é o nosso, fazer falar o território, como os psicólogos fazem falar a alma, como o Darcy Ribeiro quis fazer falar o povo, como o Celso Furtado quis falar a economia, o território também pode aparecer como uma voz. E, como do território não escapa nada, todas as pessoas estão nele, todas as empresas, não importa o tamanho, estão nele, todas as instituições também, então o território é um lugar privilegiado para interpretar o país.

Todas as pessoas e instituições se encontram no território, daí apreendê-lo como contexto, pois ele fala sobre a história do país, sobre a formação social e sobre as comunidades quilombolas. É essa história que implica nas continuidades e descontinuidades dos modos de vida, das estratégias de sobrevivência, das exclusões e das permanências. Nesse sentido, o contexto territorial pode levar ao texto quilombola, que fala de sua territorialidade.

As experiências educacionais que se desafiam a construir uma pedagogia com base na cultura dos sujeitos como os quilombolas encontram um material muito rico nas narrativas, as quais se remetem à memória e às histórias de vida. A metodologia de história oral é um importante meio de trabalho em um processo educacional. Esse método de trabalho ganha força a partir da abertura política, nos anos de 1980, quando os movimentos sociais e as vozes da cultura popular passam a ser ouvidos. A perspectiva da oralidade vai ao encontro de questões de memória e identidade, buscando a partir de questões do presente o encontro com o passado.

18 Entrevista realizada com moradora do quilombo do Cafundó - 15 maio 2014. 
Segundo Mehy (2006, p. 194 e 198), na história oral o pesquisador "acaba compreendendo para explicar, explicando para transformar". Nesse contexto, a história oral extrapola a condição de um simples instrumento e torna-se um objeto de análise central, tendo um propósito social definido, que possibilita o debate sobre um fenômeno, uma vez que sobre ele existem outras visões que ultrapassam a história oficial. Assim, pode-se dizer que: "formular outras relações que possam, em vez de 'verticalizar' as forças de dominação das memórias, 'horizontalizá-la' é mais do que ver 'memórias dominantes' ou 'memórias dominadas". Ela seria produção da história, demonstrando que cada grupo cultural/social possui sua história, tendo a condição de guardar, transmitir e construir história.

É nesse sentido que as narrativas das comunidades quilombolas se transformam em história de vida, promovendo significados às suas condições presentes ligadas ao território. $\mathrm{O}$ território tem sua fala expressa por meio do recontar o passado e atualizar tradições vinculadas à vida nos lugares para as crianças e jovens, à organização social que luta pela garantia da permanência nas terras. Reforçam, assim, as bases para a territorialidade, que nada mais é que o território vivido, mais que suporte físico, sendo elemento simbólico de poder e pertencimento. Raffestin (1993) trata da conceituação de territorialidade como um valor bem particular, remetendo-o à multidimensionalidade de viver o territorial.

A territorialidade passa a ser o ponto de partida da realidade social para a construção de um processo pedagógico significativo, pois a memória, por meio das narrativas vinculadas ao território vivido, permite a análise da história mais ampla em que se inserem as comunidades, na formação social e territorial brasileira.

Segundo Moraes (2002), a história da formação territorial brasileira mostra, a exemplo de outras colônias americanas, que após o processo emancipatório a nova ordem é construída sobre as bases estruturadas no antigo regime, cuja premissa encontrava-se no domínio dos recursos territoriais e na escravidão. No Brasil, tanto a escravidão quanto o latifúndio e a exploração das riquezas permaneceram centrais na nova ordem social e econômica. A herança escravista e o domínio fundiário influíram na sociabilidade construída:

Nesse quadro de formação nacional tem-se um território a ocupar e um Estado em construção, mas a população disponível não se ajusta à identificação de uma nação conforme os modelos identitários vigentes nos centros hegemônicos. No contexto, ao abandonar-se o caminho da construção da nacionalidade proposto por José Bonifácio (cujo eixo repousava na gradativa abolição das relações escravistas), começa a tomar corpo uma concepção que vai identificar o país não com sua sociedade, mas com seu território. Isto é, o Brasil não será concebido como um povo e sim como uma porção do espaço terrestre, não uma comunidade de indivíduos, mas com um âmbito espacial. (idem, p. 116)

Nessa formação social, o território é estatal, é do âmbito de interesses privados sobre os fundos territoriais, pertence às instâncias da racionalidade geométrica de delimitação das fronteiras e dos trajetos de passagens e integrações regionais, de amplo espectro político-administrativo e econômico e de interesses hegemônicos. 
Mas não se estabelece como cartografia da vida, da cultura, dos oprimidos e do povo. As narrativas territoriais de quilombos vêm para contrariar essa construção social e política, contando outra história: da sua permanência, dos vínculos sociais, de seus modos de vida, dos parentes e ancestrais, da origem das famílias e das terras, de diversas estratégias na formação de quilombos.

Assim, é importante demarcar que as falas dos sujeitos apresentam potencial de mudança na relação que a sociedade estabeleceu com os segmentos negros e no registro de suas identidades. A formação territorial brasileira que se constituiu negando as vivências particulares, dessa forma, passa a ser revista na medida em que se estabeleceu a visibilidade de ocupações distintas cujo movimento se traduz em registros memoriais dos territórios vividos. Conforme Arruti (2006, p. 238):

Se o território é mais evidentemente suporte e matéria da memória, respondendo aos interesses sociais e políticos da recordação, ele também acaba por operar como um condicionante sociocultural dos modos de lembrar, um meio de convencionalização da memória, isto é, de modelagem que a situação evocada sofre no contexto das ideias e valores que a evocam.

Nesse sentido, a experiência da diversidade étnica e cultural, a exemplo dos quilombos, é a contrapartida da educação nos processos de reconhecimento que ampliam o valor das leis que foram aprovadas, e as escolas, professores e educadores são desafiados a buscar caminhos que levem a múltiplas culturas para dentro dos muros da escola e para além deles, incorporando outras fontes de sabedoria não presentes na educação formal. E, por fim, atribuir valor ético e político ao processo educacional para que se modifiquem não somente os currículos escolares, mas a cultura escolar.

\section{REFERÊNCIAS}

Almeida, A.W.B.Terras de preto, terras de santo, terras de índio: uso comum e conflito. In: Castro, E.; Hebete, J. (Orgs.). Na trilha dos grandes projetos: modernização e conflito na Amazônia. Cadernos NAEA, Belém: UFPA, n. 10, p. 163-196, 1989.

. Os quilombos e as novas etnias. In: O'DWYer, E. C. (Org.). Quilombos. Identidade étnica e territorialidade. Rio de Janeiro: ABA/FGV, 2002. p. 43-81.

. Processos de territorialização e movimentos sociais na Amazônia. In: Oliveira, A. U.; Marques, M. I. M. (Orgs.). O campo no século XXI. Território de vida, de luta e de construção social da justiça social. São Paulo: Casa Amarela; Paz e Terra, 2004.p. 163-179.

.Terras de quilombos, terras indígenas, "babaçuais livres", "castanhais do povo", faxinais e fundos de pastos: terras tradicionalmente ocupadas. Manaus: PGSCA/UFAM, 2008. p. 48-49. (Projeto Nova Cartografia Social da Amazônia; coleção Tradição e ordenamento jurídico, v. 2). Disponível em: <http://novacartografiasocial.com/?wpdm act=process\&did=MTguaG90bGluaw==>. Acesso em: 16 fev. 2017.

Andrade, Y. Acesso ao ensino superior no Brasil: equidade e desigualdade social. Revista Ensino Superior Unicamp, Campinas: UNICAMP, n. 6, p. 18-27, jul./set. 
2002. Disponível em: <https://www.revistaensinosuperior.gr.unicamp.br/edicoes/ ed06_julho2012/Cibele_Yahn.pdf>. Acesso em: 20 dez. 2016.

Arruti, J. M. Mocambo. Antropologia e história do processo de formação quilombola. Bauru: EDUSC, 2006.

Bandeira, M. L. Território negro em espaço branco. São Paulo: Brasiliense; CNPq, 1988. Barth, F. Etnicidade e o conceito de cultura. Tradução de Paulo Gabriel Hilu da Rocha Pinto. AntroPolitica, Niterói: Programa de Pós-Graduação em Antropologia e Ciência Política da UFF, n. 19, p. 15-31, 2005. Dossiê: Fronteiras e Passagens: Fluxos Culturais e Construção da Identidade. Disponível em: <http://www.uff.br/antropolitica/ revistasantropoliticas/revista_antropolitica_19.pdf>. Acesso em: 20 jul. 2015.

Bosı, E. Cultura e desenraizamento. In: Bosı, A. Cultura brasileira. Temas e situações. São Paulo: Ática, 2002. p. 13-41.

Brandẽo, C. R. A educação como cultura. Campinas: Mercado de Letras, 2002.

Brasil. Constituição (1988). Constituição da República Federativa do Brasil: promulgada em 5 de outubro de 1988. "Artigo 68 do Ato das Disposições Constitucionais Transitórias que estabelece: Aos remanescentes das comunidades dos quilombos que estejam ocupando suas terras é reconhecida a propriedade definitiva, devendo o Estado emitir-lhes os títulos respectivos”. Diário Oficial da União, Brasília, DF: Presidência da República, 5 out. 1988.

. Constituição (1988). Constituição da República Federativa do Brasil: promulgada em 5 de outubro de 1988. "Artigo 215, de 5 de outubro de 1988. § 1o Seção II - Da Cultura. Título VIII - Da Ordem Social. Capítulo III - Da Educação, da Cultura e do Desporto. Define que o Estado protegerá as manifestações das culturas populares, indígenas e afro-brasileiras, e das de outros grupos participantes do processo civilizatório nacional”. Diário Oficial da União, Brasília, DF: Presidência da República, 5 out. 1988.

. Constituição (1988). Constituição da República Federativa do Brasil: promulgada em 5 de outubro de 1988. "Artigo 216, de 5 de outubro de 1988. § 5o Título VIII - da Ordem Social. Capítulo III - Da Educação, da Cultura e do Desporto Seção II Da Cultura. Estabelece que ficam tombados todos os documentos e os sítios detentores de reminiscências históricas dos antigos quilombos”. Diário Oficial da União, Brasília, DF: Presidência da República, 5 out. 1988.

Lei n. 7.668, de 22 de agosto de 1988. Autoriza o Poder Executivo a constituir a Fundação Cultural Palmares - FCP e dá outras providências. Diário Oficial da União, Brasília, DF: Presidência da República, 23 ago. 1988.

. Decreto n. 4.887, de 20 de novembro de 2003. Regulamenta o procedimento para identificação, reconhecimento, delimitação, demarcação e titulação das terras ocupadas por remanescentes das comunidades dos quilombos de que trata o art. 68 do Ato das Disposições Constitucionais Transitórias. Diário Oficial da União, Brasília, DF: Presidência da República, 21 nov. 2003.

. Resolução CNE/CEB n. 8, de 20 de novembro de 2012. Define as Diretrizes Curriculares Nacionais para a Educação Escolar Quilombola na Educação Básica. Diário Oficial da União, Brasília, DF: MEC/CNE/CEB, 21 nov. 2012. Seção 1, p. 26. 
. Resolução CD/FNDE n. 26, de 17 de junho de 2013. Conselho Deliberativo. Fundo Nacional de Desenvolvimento da Educação. Dispõe sobre o atendimento da alimentação escolar aos alunos da educação básica no âmbito do Programa Nacional de Alimentação Escolar - PNAE. Diário Oficial da União, Brasília, DF: MEC/CD/ FNDE, 18 jun. 2013.

.Ministério da Educação. Instituto Nacional de Estudos e Pesquisas Educacionais Anísio Teixeira. Censo Escolar da Educação Básica de 2013. Brasilia: MEC/INEP, 2014.

CArriL, L. F. B. Terras de negros no vale do Ribeira: territorialidade e resistência. 1995. 212f. Dissertação (Mestrado em História Social) - Universidade de São Paulo, São Paulo, 1995.

Carvalho,J. M. Os bestializados da República. 3. ed. São Paulo: Companhia das Letras, 2006.

DiAs, T. S. Educação escolar quilombola no censo da educação. Rio de Janeiro: IPEA, abr. 2015.p. 13 e 21.

Diegues, A. C. S. O mito moderno da natureza intocada. São Paulo: Hucitec, 1996.

Freire, P. $A$ importância do ato de ler: em três artigos que se completam. 48. ed. São Paulo: Cortez, 2006.

Giroux, H. A. Os professores como intelectuais. Rumo a uma pedagogia crítica da aprendizagem. Porto Alegre: Artmed, 1997.

Guimarães, A. S. A. Como trabalhar com raça em sociologia. Educação e Pesquisa, São Paulo: FEUSP, v. 29, n. 1, p. 93-107, jan./jun. 2003. Disponível em: <http://www.scielo. $\mathrm{br} / \mathrm{pdf} / \mathrm{ep} / \mathrm{v} 29 \mathrm{n} 1 / \mathrm{a} 08 \mathrm{v} 29 \mathrm{n} 1 . \mathrm{pdf}>$. Acesso em: 20 jul. 2014.

Halbwachs, M. A memória coletiva. São Paulo, Centauro: 2006.

Honneth, A. Luta por reconhecimento. A gramática moral dos conflitos sociais. São Paulo: Editora 34, 2003.

ibGe - Instituto Brasileiro de Geografia e Estatística. Censo Demográfico 2010. IBGE, Rio de Janeiro, 27 abr. 2012. Disponível em: <http://www.ibge.gov.br/ home/presidencia/noticias/imprensa/ppts/00000008473104122012315727483985. pdf $>$. Acesso em: 30 jul. 2015.

IneP - Instituto Nacional de Estudos e Pesquisas Educacionais Anísio Teixeira. Censo escolar da educação básica 2013: caderno de instruções. Brasília: INEP, 2013.

IPEA - Instituto de Pesquisa Econômica Aplicada. Educação escolar quilombola no Censo da Educação Básica. IPEA, Rio de Janeiro, abr. 2015. Texto para discussão organizado por Tatiana Dias Silva. Disponível em: <http://www.ipea.gov.br/agencia/ images/stories/PDFs/TDs/td_2081.pdf.>. Acesso em: 20 jul. 2015.

LARA, S. H. Do singular ao plural: Palmares, capitães do mato e o governo dos escravos. In: ReIs, J.J.; Gomes. F. S. Liberdade por um fio. História dos quilombos no Brasil. São Paulo: Companhia das Letras, 1996. p. 97 e 108.

LEFEBVRE, H. La presencia y la ausencia: contribución a la teoría de las representaciones. México: Fundo de Cultura Econômica, 1983. 
Machado, C. E. D. População negra e escolarização na cidade de São Paulo nas décadas de 1920 e 1930. 2009. 154f. Dissertação (Mestrado em História Social) - Universidade de São Paulo, São Paulo, 2009.

Manson, A. K. EJA e mulher negra: vencendo pedras no caminho à emancipação. 2009. 66f. Monografia (Especialização em Proeja) - Instituto Federal de Educação, Ciência e Tecnologia São Paulo, São Paulo, 2009.

Meny, J. C. B. Os novos rumos da história oral: o caso brasileiro. Revista de História, São Paulo: Departamento de História da USP, v. 2, n. 155, p. 191-203, 2006. Disponível em: <http://www.revistas.usp.br/revhistoria/article/view/19041/21104>.Acesso em: 20 jun. 2015. Melo, R. Da teoria à práxis? Axel Honneth e as lutas por reconhecimento na teoria política contemporânea. Revista Brasileira de Ciência Politica, Brasília, DF: Instituto de Ciência Política da UnB, n. 15, p. 17-36, set./dez. 2014.

Miranda, S. A. Educação escolar quilombola em Minas Gerais: entre ausências e emergências. Revista Brasileira de Educação, Rio de Janeiro: ANPEd; Campinas: Autores Associados, v. 17, n. 50, p. 369-498, maio/ago. 2012.

Moraes, A. C. R. Território e história no Brasil. São Paulo: Annablume/Hucitec, 2002. Moura, C. Os quilombos e a Rebelião Negra. São Paulo: Brasiliense, 1981. (coleção Tudo é história)

Nobre, M. A teoria crítica. Rio de Janeiro: Zahar, 2004. (coleção Filosofia passo a passo, 47)

PAssos, J. C.Juventude negra na EJA: os desafios de uma política pública. 2010.339f. Tese (Doutorado em Educação) - Universidade Federal de Santa Catarina, Florianópolis, 2010.

Pires, A. A. et al. (Orgs.). Dona Ifigênia. Existência e resistência do povo cafundó. São Paulo: Secretaria de Cultura do Estado de São Paulo, s/d.

Raffestin, C. Por uma geografia do poder. São Paulo: Ática, 1993.

Ratts, A. J. P. (Re) Conhecer quilombos no território brasileiro. In: FonsecA, M. N. S. (Org.). Brasil afro-brasileiro. Belo Horizonte: Autêntica, 2010a. p. 307-327.

- Geografia, relações étnico-raciais e educação: a dimensão espacial das políticas de ações afirmativas no ensino. Terra Livre, São Paulo: AGB, ano 26, v. 1, n. 34, p. 125-140, jan./jun. 2010b. Disponível em: <https://www.academia.edu/5127658/ Geografia_relacoes_étnico-raciais_e_educação>. Acesso em: 27 jun. 2015.

Santos, M. Entrevista com Milton Santos. Entrevistadores: M. Amaral, S. P. de Almeida, L. G. Ribeiro, G. Bourdoukan, R. Freire, J. Noro, S. de Souza. Caros Amigos, São Paulo, n. 17, ago. 1998. Disponível em: <http://www.carosamigos.com.br/index. php/grandes-entrevistas/6047-entrevista-explosiva-com-milton-santos >. Acesso em: 20 jul. 2015.

Schwarcz, L. M. O espetáculo das raças. Cientistas, instituições e questão racial no Brasil (1870-1930). São Paulo: Companhia das Letras, 1993.

Schwarz, R. Ao vencedor as batatas. Forma literária e processo social nos inícios do romance brasileiro. 6. ed. São Paulo: Duas Cidades; Editora 34, 2012. 
SER PA, A. Teoria das representações em Henri Lefebvre: por uma abordagem cultural e multidimensional da geografia. GEOUSP - Espaço e Tempo, São Paulo: Departamento de Geografia, USP, v. 18, n. 3, p. 487-495, 2014. Disponível em: <http://www.revistas. usp.br/geousp/article/view/83538>. Acesso em: 24 maio 2015.

Sodré, M. Cultura, diversidade cultural e educação. In: Trindade, A. (Org.). Multiculturalismo. Mil e uma faces da escola. Rio de Janeiro: DP\&A, 2002.

UNESCO - Organização das Nações Unidas para a Educação, a Ciência e a Cultura. Relatório Educação para Todos 2000-2015: progressos e desafios. Paris. Disponível em: <http://www.unesco.org/new/pt/brasilia/education/education-for-all/>. Acesso em: 10 jul. 2015.

VIdal, D. G. 80 anos do Manifesto dos Pioneiros da Educação Nova: questões para debate. Educação e Pesquisa, São Paulo: FEUSP, v. 39, n. 3, p. 577-588, jul./set. 2013. Disponível em: <http://www.scielo.br/pdf/ep/v39n3/aop1177.pdf >. Acesso em: 2 jul. 2015.

Vogt, C.; Fry, P. Cafundó. A África no Brasil. São Paulo: Companhia das Letras, 1996. WeIL, S. O enraizamento. In:__ A condição operária e outros estudos sobre a opressão. 2. ed. Rio de Janeiro: Paz e Terra, 1996. p. 411-412. (Antologia organizada por Ecléa Bosi)

\section{SOBRE A AUTORA}

Lourdes de Fátima Bezerra Carril é doutora em geografia humana pela Universidade de São Paulo (USP). Professora da Universidade Federal de São Carlos (UFSCar).

E-mail: lourdescarril@ufscar.br

Recebido em 16 de agosto de 2015 Aprovado em 11 de fevereiro de 2016 